\title{
EL PERSONALISMO CRISTIANO COMO PROPUESTA PARA ENSENAR Y APRENDER FILOSOFÍA
}

Juan Bautista Duhau*

\section{Resumen}

Plantea una selección de contenidos y un modo de abordarlos a través de distintas actividades pedagógico didácticas, que presentan el personalismo cristiano como una propuesta filosófica de gran riqueza para ser utilizada en el marco de la educación media. Explicitando una concepción de Filosofía, de su enseñanza y aprendizaje, que, partiendo de una mirada de raigambre personalista sobre el ser humano, propone que los participantes de la actividad escolar se descubran como personas con capacidad de pensar, reflexionar y dar cuenta de lo que piensan. Tam-

* Ingeniero Agrónomo. Profesor en Ciencias Agrarias (Universidad Nacional del Sur, Argentina). Profesor de Filosofía (Instituto Superior Juan XXIII, Obra de Don Bosco, Arg.) y Bach. en Teología (Instituto Superior de Estudios Teológicos Cristo Buen Pastor; Arg., afiliado a la Facultad de Teología de la Universidad Pontificia Salesiana de Roma). Docente del Área Humanística en el Colegio San José de la Palabra de Dios, Ciudad Autónoma de Buenos Aires, Argentina. 
bién realza el valor del uso de un blog de cátedra para el trabajo de los alumnos.

\section{Introducción}

A partir de la experiencia docente como profesor de Antropología Filosófica en el último curso de un colegio de nivel medio confesional de la Ciudad Autónoma de Buenos Aires, Argentina, me propongo señalar que la filosofía personalista y, dentro de esta escuela: el personalismo cristiano, ofrece una riqueza de propuestas capaces de dinamizar la actividad aúlica, generando un clima de reflexión y discusión que parta del planteo teórico filosófico para responder preguntas de los alumnos sobre su vida cotidiana.

También presentaré una selección de contenidos y temáticas que han contribuido a motivar a los alumnos, así como modos de trabajo con el uso de las nuevas tecnologías tanto para el desarrollo del cursado de la asignatura como para las instancias de evaluación.

\section{Partimos de una concepción de la filosofía}

Toda nuestra práctica educativa puede ser catalogada de actividad filosófica en la medida en que se convierte en un proceso de análisis, búsqueda y explicitación de los supuestos subyacentes; cuando se vuelve un camino de desvelamiento de las relaciones existentes entre las distintas temáticas y situaciones; cuando crítica y creativamente pone en cuestión los valores sociales y los valores del currículum escolar.

Lo propio de la Filosofía en la escuela estaría dado, según Cerletti y Kohan ${ }^{1}$, por ofrecer a los estudiantes una 
serie de elementos teóricos y metodológicos, una apertura al pensamiento crítico y creativo, que les permita poner en práctica una filosofía que se pregunte acerca de los supuestos, métodos y fundamentos de cada disciplina (Ciencias Naturales, Literatura, Historia, etcétera). De esta manera las otras disciplinas pueden resultar ámbito de aplicación de esta capacidad cuestionadora que la Filosofía moviliza.

Pero, por otra parte, la Filosofía tiene un ámbito propio que le viene dado por un campo problemático que no comparte con ninguna disciplina escolar; se trata de problemas o temáticas que ningún otro saber trata y que son específicamente filosóficas.

$\mathrm{Al}$ inicio del ciclo lectivo todos los docentes presentamos nuestras propuestas a los alumnos. En este caso, para comenzar a presentar la filosofía a alumnos adolescentes de 17 años, que fácilmente pueden considerar el abordaje filosófico como aburrido y lejano a la propia realidad, los animo con un texto motivador que da cuenta de la concepción de la Filosofía como cátedra y su "utilidad".

\section{Profe, ¿para qué estudiamos Filosofía?}

Imaginemos un diálogo hipotético que se inicie con esta expresión, que puede ser interpretada por el resto del aula como el reclamo de un alumno de aquellos caraduras del curso. Imagino entonces mi respuesta como docente: - Mirá, lo podemos charlar, pero creo que primero deberíamos preguntar: ¿Qué es la filosofía?

La filosofía es la posibilidad de pensar, de reflexionar, de ganar espacios en nuestros pensamientos y en nuestro corazón para averiguar lo que nos pasa. Lo que nos pasa acá en el aula, después en el recreo, cuando volvés a tu casa, cuando prendés la tele, cuando te co- 
nectás a chatear con tus amigos o con la chica que conociste en el boliche. Eso es filosofía.

Filosofía es buscar y rescatar de la memoria de los pueblos la manera en que otras mujeres y otros hombres se animaron a posponer otras cosas para meditar y juzgar su realidad, para buscar profundamente las raíces de su vida y de su existencia. Eso es filosofía.

Filosofía es dar cuenta de lo que me pasa y le pasa al otro, es la posibilidad de hablar y escuchar, de escucharnos y de escucharnos buscar, buscar en nosotros, en lo hondo de nosotros las preguntas mudas para que sean dichas y encuentren respuestas que nos hablen todavía más hondo. Eso es filosofía.

Filosofía es preguntarse ¿qué es el hombre?, y animarnos a decirnos hombres y mujeres de verdad y observar si este mundo nos dice hombre o nos dice persona o nos dice animal o, quizá, no nos diga nada. Eso es filosofía.

Filosofía es aprender a amar la posibilidad de saber, de pensar y de reflexionar, y en esa tarea - porque el amor es un don y una tarea-, el amor nos va personalizando. Cuando te animás a hablar con tu compañero sobre el hombre, la trascendencia, el amor; cuando lo escuchás y te escuchás y nos escuchamos dejamos de decir 'che, boludo!'2 para ver en el otro a Jorge, a Ana, a la persona que está a mi lado todas las mañanas. Eso es filosofía.

Filosofía es un montón de palabras; hombre, mundo, libertad, amor, trascendencia, conocimiento, virtud, duda, pregunta, asombro, moral, política, guerra y paz, soledad, incertidumbre y certeza, igualdad, todos, nadie, nada, diferencia y mucho más. Tanto más cómo vos querás, como nosotros querramos buscar y preguntar. Eso es filosofía. 
Y filosofía es nunca bastante. Porque nunca llegamos a la respuesta, nunca alcanzamos a la filosofía, ella nos alcanza y nos llena de preguntas una vez más. Eso es filosofía...

—Profe, ¿me convida una pastilla?

Desde nuestra visión, la clase de Filosofía se debería caracterizar por su capacidad de análisis crítico de la realidad, que se inicia como propuesta de problematización por parte del docente, que aporta herramientas en la tarea pedagógica de buscar resolver las problemáticas planteadas por los grandes temas de la filosofía y por las temáticas que llegan al aula desde lo social, los medios de comunicación y también desde la realidad vivida y compartida por los alumnos.

Por eso, la clase de Filosofía deberá intentar promover en sus alumnos una actitud filosófica; es allí donde los textos filosóficos serán una herramienta central para el filosofar.

La clase en que los alumnos no se sientan movilizados hacia la búsqueda de la verdad y la investigación filosófica termina provocando hartazgo y anulando toda iniciativa de trabajo comprometido. La motivación debe ser un eje fundamental de la clase de Filosofía, donde el docente debe abrir los ojos a las posibilidades que brinda el arte, los medios de comunicación y la misma informática, para atraer al alumno desde lo más cercano a él y llevarlo hacia las cuestiones filosóficas subyacentes a toda realidad humana.

En el contexto en el que se plantea la enseñanza de la filosofía se debe contar con el diálogo como herramienta, entendido este como un diálogo argumentativo, como un contenido procedimental junto con los contenidos conceptuales y los contenidos actitudinales. La filosofía 
se vale del diálogo como recurso, hace de la práctica educativa una práctica dialógica, que nutre el pensar filosófico, manifiesta el carácter problemático y cuestionador, ofrece posiciones que, confrontadas, se alimentan mutuamente.

Otro de los importantes aspectos a destacar de la práctica es la necesidad de la apropiación de ciertas habilidades lógico argumentativas o cognitivas, indispensables para el desarrollo de un pensar sistemático, que constituyen una condición para el filosofar y no un fin en sí mismas.

La clase de Filosofía necesita de múltiples habilidades de pensamiento: dar razones, distinguir las razones de las pseudorazones, establecer conexiones y distinciones, clarificar conceptos, sentidos y significaciones, entender y aplicar relaciones de parte/todo y medio/fin, trazar analogías, formular, usar y remover criterios, entender y evaluar argumentos (reconocer falacias y contradicciones), identificar, justificar y cuestionar supuestos, anticipar, predecir y explorar consecuencias, etcétera

¿Para qué esta materia, este año, en mi vida? Esta es la pregunta que buscamos responder en el laborioso diálogo del aula, siempre con el horizonte de descubrirnos personas; personas con capacidad de pensar, de reflexionar y de dar cuenta de lo que pensamos. Ser capaces de conciencia sobre nosotros mismos, de decirnos quiénes somos y qué queremos. ¿Y para qué? Para poder decir soy yo y no soy lo que me imponen. Para no ser una subjetividad controlada, sino una persona capaz de elegir y vivir en libertad, capaz de amar y trabajar en libertad.

También para poder poner en palabras, encontrar palabras para expresar las preguntas, los ideales que el corazón joven inevitablemente lleva dentro suyo y busca exteriorizar de modos diversos. También, uno de los objetivos de la asignatura será mostrar caminos prácticos para que los alumnos puedan encontrar palabras que expresen su mundo interno. Como dice Juan Gelman: "El día que el 
corazón aprenda a leer y a escribir se verán cosas grandes [...] Será un gran día, encontrará la palabra que se perdió hace millones de dolores" (Gelman, 2004: 94). Así el ejercicio de la filosofía es la posibilidad de encontrar la palabra olvidada para poder plasmarla como comunicación de vida en medio del mundo.

\section{... y de una mirada sobre el hombre}

Vivimos dentro de la revolución premonitoriamente anunciada por Nietzsche, quién profetizó los tiempos de la muerte de Dios y la divinización del hombre; con la muerte de Dios el futuro no está en manos de nadie más que del hombre y por ello carece de sentido hablar de salvación ${ }^{3}$. La sed de trascendencia, el sentido del obrar del hombre, no puede ser resuelto por las ideologías contemporáneas que identifican destino con finalidad del hombre en una praxis histórica. En este sentido, las tradiciones religiosas pueden jugar un papel muy significativo en la elaboración de un marco ético común y un horizonte global de sentido para la vida del hombre ${ }^{4}$. Decir que la persona solo es aquello que realiza en su vida mundana y que su vida, toda su vida, se define en el devenir de la praxis humana no alcanza al corazón del hombre, pues no colma la sed de sentido de la existencia que se expresa en la necesidad de contar con un puerto de llegada, un destino para el derrotero de la existencia. El desconcierto posmoderno ha alcanzado al concepto de sentido del obrar humano, el "para qué hacemos lo que hacemos".

Se trata de la sed de trascendencia, de la sed de Dios, que permanece firme en el hombre a pesar de los tiempos; lo dice el profeta antiguo: "Había en mi corazón algo así como fuego ardiente, prendido en mis huesos, y 
aunque yo trabajaba por ahogarlo, no podía” (Jer 20, 9b.) y lo reafirma el poeta contemporáneo:

es frecuente que un hombre se revise la frente hallándote debajo encendida apagada es frecuente que sucedan estas cosas mi Dios con un hombre que será destruido y no te arrancarán de su sed ${ }^{5}$.

Esta sed de resolver los enigmas de la vida y de descubrir aquellas cosas que encierran el sentido profundo de la existencia es una necesidad que no ha perdido vigencia a lo largo del desarrollo de la cultura moderna y es por eso que las ciencias sociales continúan en la búsqueda de

un paradigma que permita superar la cultura del crecimiento de las ambiciones individuales, del exceso de autonomía de los individuos y grupos elitistas que no tienen en cuenta el bien de las otras personas; de superar la rivalidad crónica que a menudo es motivo de conductas agresivas; y también de la creciente desproporción entre un estrato de gente que se enriquece de manera injusta y gente que es marginada en la miseria, el desempleo y la falta de vivienda (Gallagher, 1997: 199).

Al hacer una propuesta a los alumnos encontramos que el personalismo cristiano es una perspectiva filosófica que responde a este paradigma que hoy buscan las Ciencias Sociales y que encierra un potencial crítico y propositivo capaz de ser utilizado en la programación de un currículo escolar en el área de la Filosofía.

Al hablar de personalismo nos estamos refiriendo a la perspectiva filosófica iniciada por Emmanuel Mounier (Grenoble, 1905-Châtenay-Malabris, 1950) y que se ha expandido en múltiples ramificaciones conformando un gran árbol [cómo apreciamos en la ilustración ${ }^{6}$ ], en palabras de José Francisco Serrano, quien señala: 
El árbol de la ciencia del personalismo se nutre de la savia de la rama Péguy: Péguy, Maritain, Mounier, Domenach, Lacroix, Berdiaev y Manzana; de la rama de Scheler: von Hildebrand, Landsberg y Xirau; de la rama fenomenológica-tomista: Wojtyla, Stein y Nédoncelle; de la rama Zubiri: Zubiri, Ellacuría, Aranguren y Laín; de la rama dialógica: Rosenzweig, Buber, Lévinas, Kierkegaard, Ebner, Brunner, Marcel, Guardini, Ruíz de la Peña, Manjón, Marías - padre, por supuesto-; y de la rama hermenéutica: Ricoeur?

Figuras del PERSONALISMO

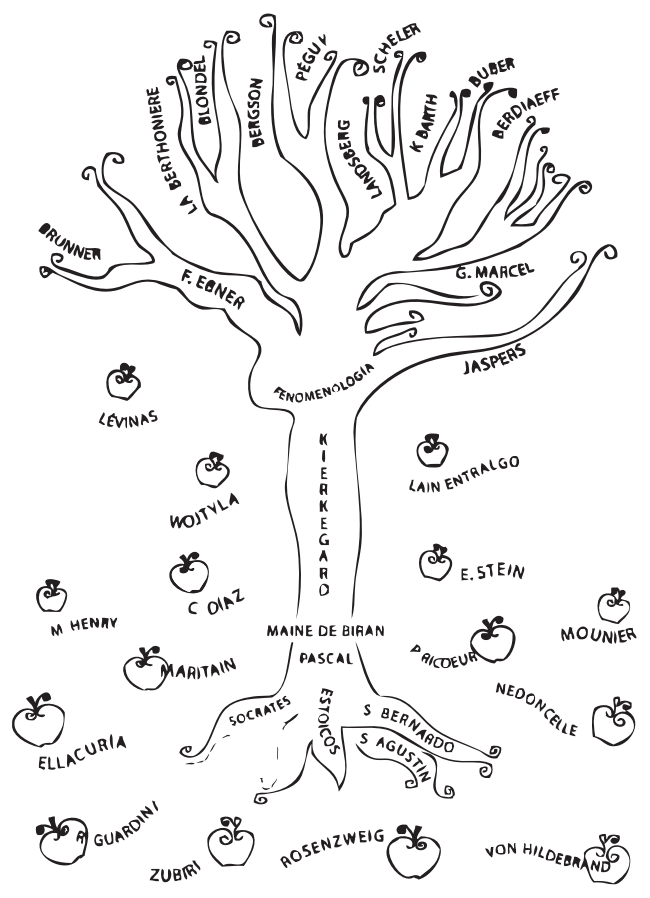


No es el objetivo de este artículo describir la variedad de temáticas y el modo de abordarlas del personalismo cristiano, pero es necesario destacar que este centra su atención en la persona humana, no como un objeto acabado, sino como...

una actividad vívida de autocreación, de comunicación y de adhesión que se aprehende y se conoce en su acto, como movimiento de personalización. Así la persona humana constituye pues el eje y el valor clave del pensamiento personalista" (Guita, 1999: 26).

\section{...para hacer una propuesta de contenidos}

¿Qué contenidos proponer a los alumnos de un último año de estudios de nivel medio en una asignatura que busca introducirlos en la filosofía desde el tema antropológico? En general, los docentes nos encontramos en serios dilemas al concentrarnos en la tarea de la selección de contenidos o autores frente a lo vasto de esta área de estudios.

Nos hemos planteado varios objetivos frente a la selección de contenidos: realizar propuestas claras, concretas y, sobre todo, realizables; no dejar de lado temáticas que se abordan en los años iniciales de la formación superior en las materias humanísticas (por ejemplo, el materialismo histórico marxista) o perspectivas filosóficas de discusión actual (como el nihilismo nietzcheano); presentar el pensamiento filosófico desde o por medio de planteos sociales cercanos a la vida de los adolescentes para provocar el pensamiento crítico; y por último, la utilización del contenido filosófico como herramienta para la comprensión del hombre y del hombre encarnado en nuestra realidad concreta. 
Frente a lo ambicioso de nuestras metas y lo amplio de la disciplina, nuestra selección de contenidos abordó como temas introductorios las distintas concepciones de la filosofía, sus orígenes, sus preguntas y la tarea del filósofo, para luego presentar la temática antropológica desde el discurso filosófico. Para el desarrollo de estos temas la bibliografía es amplia y existen variedad de materiales que permiten su aplicación en el aula, que no detallaremos pues preferimos reseñar el modo en que hemos abordado diversos aspectos de la antropología filosófica teniendo como base el personalismo cristiano.

Iniciados en la temática de la Antropología Filosófica buscamos dar cuenta del planteo filosófico del personalismo cristiano y el pensamiento personalista de Emmanuel Mounier utilizando distintos materiales:

- Un capítulo de una Tesis de Licenciatura:

Guita, María Estela, El personalismo cristiano en "Educación y valores en adolescentes de la posmodernidad desde una perspectiva personalista". Tesis de la Lic. en Ciencias de la Educación, Universidad Católica de Córdoba, 1999: 24-36.

- Artículos web sobre la temática: Vaquero Oroquieta, Fernando José, El movimiento personalista en España, en ARBIL, Anotaciones de Pensamiento y Crítica, No 61, Foro Arbil, Zaragoza, España, en 〈http://www.arbil.org/arbi-d61.htm〉, última vista 05/04/2011.

Calvo, Antonio, El personalismo de E.Mounier, en ARBIL, Anotaciones de Pensamiento y Crítica, No 61, Foro Arbil, Zaragoza, España, en 〈http://www. arbil.org/arbi-d61.htm>, última vista 05/04/2011.

- Archivos sonoros publicados en blog de cátedra. 
Emmanuel Mounier: el personalismo cristiano, podcast del programa "La Estrella Polar" emitido en canal COPE el 21/02/2009 y disponible online en 〈http://www. ivoox.com/emmanuel-mounier-personalismo-cristiano md_46346_1.mp3 , última vista 02/04/2011.

Como instancia de evaluación se propone a los alumnos una producción escrita que parte, como elemento motivacional también, de la proyección y/o disponibilidad en el blog de cátedra del video-clip de la canción ¿Dónde está el amor? del grupo estadounidense de R\&B, pop y hip hop, The Black Eyed Peas ${ }^{8}$. A continuación presentamos una traducción personal del tema musical que nos permitirá percibir cómo encontrar puntos de contacto entre la cultura cercana a nuestros jóvenes y el planteo filosófico estudiado.

¿Qué le pasa al mundo, mamá?

La gente vive como si no tuviera familia.

Creo que el mundo entero es adicto a los dramas,

Atraídos solamente por las cosas que solo dan traumas.

A toda costa queremos detener el terrorismo,

Pero tenemos terroristas aquí,

En los EUA, la 'gran' CIA, los Bloods, los crips, y el KKK.

Y si tú solo amas a tu propia raza,

Entonces discriminas.

Y discriminar solo genera más odio.

Cuando odias te pones furioso.

Así es, demuestras maldad.

y así es exactamente como funciona y opera el enojo.

Tienes que amar para hacer lo correcto.

Toma control de tu mente y medita.

Deja que tu alma flote hacia el amor.

Gente matando, gente muriendo.

Niños heridos a los que escuchas llorar.

¿Puedes practicar lo que predicas? 
¿Pondrías la otra mejilla?

Padre, Padre, Padre, ayúdanos.

Envíanos alguna señal desde arriba.

Porque la gente sigue preguntándome

¿Dónde está el amor?

¿Dónde está el amor? (el amor) [bis]

Nunca será lo mismo, todo ha cambiado.

Cada día es muy extraño, ¿está loco el mundo?

Si el amor y la paz son tan fuertes, ¿por qué hay piezas de amor que no encajan?

Naciones bombardeando, gases químicos llenando los pulmones de algunos

mientras sufren y la juventud muere joven.

Entonces pregúntate: ¿ha desaparecido el amor?

Entonces me pregunto:

¿Qué está mal en este mundo en el que vivimos?

La gente sigue siendo egocéntrica.

Tomando decisiones equivocadas.

Tomando en cuenta solo su vida sin respetar a los demás.

Negando a su hermano.

Las guerras continúan pero las razones se ocultan.

La verdad se mantiene en secreto, está oculta.

Si no conoces la verdad, entonces no conoces el amor.

¿Dónde está el amor? — No lo sé.

¿Dónde está el amor? — No lo sé.

¿Dónde está el amor?

Gente matando, gente muriendo.

Niños heridos a los que escuchas llorar.

¿Puedes practicar lo que predicas?

¿Pondrías la otra mejilla?

Padre, Padre, Padre, ayúdanos.

Envíanos alguna señal desde arriba.

Porque la gente sigue preguntándome

¿Dónde está el amor?

¿Dónde está el amor? (el amor) [bis ]

Siento el peso del mundo sobre mis hombros. 
A medida que me hago mayor,

la gente se vuelve más fría.

La mayoría de nosotros

solo se preocupa en hacer dinero.

El egoísmo nos tiene siguiendo el camino equivocado.

Desinformación es lo que se muestra en los medios.

Imágenes negativas son los principales criterios.

Infectando sus mentes jóvenes

más rápido que las bacterias.

Los niños actúan como lo que ven en el cine.

Lo que sea que haya pasado con los valores humanos.

Lo que sea que haya pasado con la imparcialidad

y la igualdad.

En vez de promover el amor, promovemos rencor.

La carencia de entendimiento nos separa más y más.

$Y$ esa es la razón por la que a veces me deprimo.

Y esa es la razón por la que a veces me canso.

No hay razón por la que a veces me deprima.

Mi fe permanecerá viva hasta que encuentre el amor.

Gente matando, gente muriendo.

Niños heridos a los que escuchas llorar.

¿Puedes practicar lo que predicas?

¿Pondrías la otra mejilla?

Padre, Padre, Padre, ayúdanos.

Envíanos alguna señal desde arriba.

Porque la gente sigue preguntándome

¿Dónde está el amor?

¿Dónde está el amor? (el amor) [bis]

La evaluación presentada pide a los alumnos establecer relaciones entre el contenido de la canción, ya sea en su letra como en el soporte visual de la canción, y los planteos de la filosofía personalista, fundamentando adecuadamente de acuerdo a la bibliografía abordada en clase. Los criterios de corrección que se establecen son entrega en tiempo y forma, originalidad (no copia), corrección or- 
tográfica y gramatical, coherencia del texto, pertinencia de los conceptos utilizados.

Luego, a partir del pensamiento personalista y específicamente del personalismo cristiano de Mounier, se fueron planteando una serie de grandes ejes, que, de acuerdo a las posibilidades de calendario escolar y los distintos grupos aúlicos, se fueron seleccionando para trabajar en los distintos ciclos escolares.

\section{- El cuerpo y la corporalidad}

Partiendo de la realidad juvenil que hace del tatuaje un modo de expresión, y que está muy presente entre los adolescentes argentinos de toda clase social, nos propusimos reflexionar sobre el cambio de mirada sobre el cuerpo que avala este comportamiento social y contrastarlo con el valor positivo que ha dado al cuerpo la moderna Antropología Filosófica.

Para la motivación se propuso la lectura de fragmentos del texto Biografía de la piel, esbozo para una enciclopedia del tatuaje que presenta el tatuaje y su universo e intenta analizarlo desde una perspectiva estructuralista. Para el trabajo de reflexión filosófica se abordo el capítulo "La persona y su cuerpo" del Manual de Bioética de Elio Sgreccia (1996).

La evaluación se presentó como una discusión a través de comentarios a una afirmación extraída del texto filosófico en el blog de cátedra.

La consigna de evaluación fue la siguiente:

Los comentarios deberán tener una extensión no menor de 100 palabras, contar con el nombre del autor y realizarse antes del 16 de octubre en 〈http://acercadelhombre.blogspot.com». 
Lo que es propio de mi cuerpo es el no existir por sí solo, el no poder existir por sí solo" Se puede decir: "yo soy mi cuerpo", con la condición de que no se entienda en sentido exhaustivo, para afirmar que nosotros solo somos cuerpo; puede decirse "YO soy mi cuerpo", con tal que no se entienda que este es simplemente un objeto (G. Marcel).

\section{- La libertad de la persona humana}

En esta sección nos propusimos analizar el valor y la importancia que da el hombre a su libertad, buscando comprender la diferencia entre heteronomía y autonomía y valorando la importancia que tiene para el hombre desarrollar un discernimiento moral autónomo. Iniciamos el trabajo identificando el modo de presentar la libertad y sus características en un cantautor contemporáneo, Andrés Calamaro; ; para luego contrastar con el concepto de libertad desde los autores personalistas y profundizar en los conceptos de autonomía-heteronomía. Este abordaje nos permitió reflexionar con los alumnos sobre los procesos personales de toma de decisiones a partir de las tres dimensiones de la libertad que van a caracterizar la educación personalista: libertad de elección, libertad de ruptura y libertad de adhesión.

Para el abordaje del marco teórico se utilizaron redes conceptuales elaboradas por el docente, metodología que se busca transmitir a los alumnos y enseñar a construir y utilizar ${ }^{10}$. 


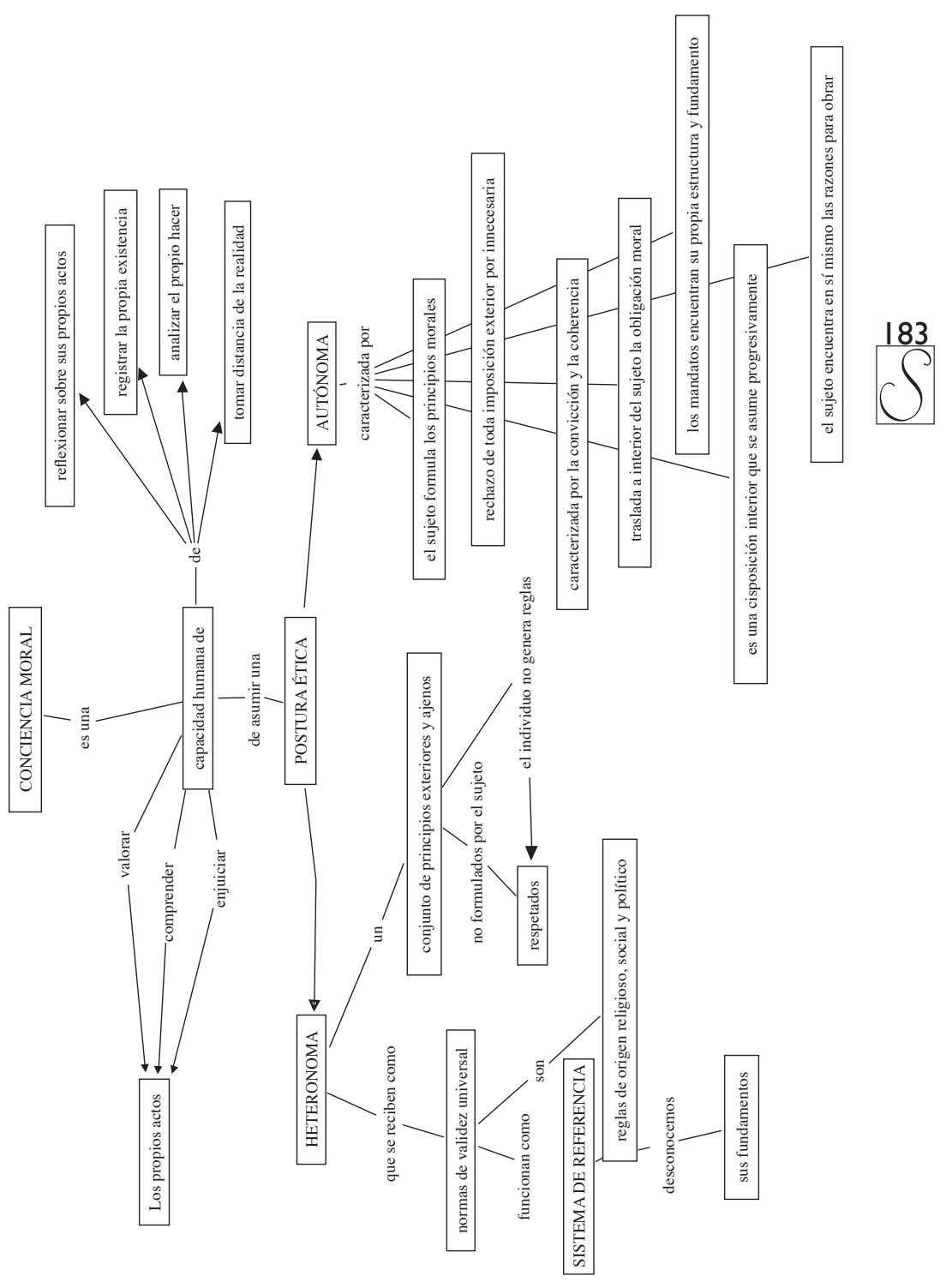




\section{- El materialismo histórico marxista}

En muchas casas de educación superior, en los cursos iniciales, los alumnos se enfrentan a la lectura de textos introductorios a la sociología como puede ser el Manifiesto Comunista de Karl Marx. Por ello nos parece importante poder abordar la crítica marxista al capitalismo y el concepto de alienación del hombre a través de la lectura guiada de este Manifiesto para ir emitiendo juicios sobre los modos de resolución que presenta esta filosofía y comparándolos con las propuestas realizadas por Mounier. La crítica del fundador del personalismo al capitalismo es también radical ya que lo considera el "principal agente de opresión de la persona humana en el seno de la historia", pero frente al individualismo liberal y el colectivismo marxista presenta la propuesta del amor centrada en una filosofía del nosotros ${ }^{11}$. Así nos permitimos entrar en la escuela marxista dialogando con su pensamiento y con capacidad de confrontar constructivamente desde un pensamiento de base cristiana.

\section{- El hombre y la posmodernidad}

Finalmente buscamos dar cuenta de la mirada del hombre en el marco de la posmodernidad. Se analiza el camino atravesado por la humanidad para llegar a esta etapa tras la modernidad presentando el pensamiento de Friedrich Wilhelm Nietzsche. Luego reflexionamos cómo desempeñan un papel determinante los medios de comunicación en el nacimiento de la sociedad posmoderna desde las posturas contrapuestas de Gianni Vattimo (1990) y Giovanni Sartori (1998). Se utilizan metodologías de lectura y discusión grupal para los textos de Vattimo y Sartori. Para el abordaje del pensamiento nietzcheano se propone la lectura del fragmento No 135 de La gaya ciencia y su análisis a 
través de la construcción de una red conceptual en forma individual o en pequeños grupos que se ponen en común mediante proyección. El docente parte del análisis realizado por los alumnos y, apoyado en su propia red conceptual, busca mostrar a los alumnos un modo de abordaje del texto filosófico que permita desentrañarlo y comprenderlo.

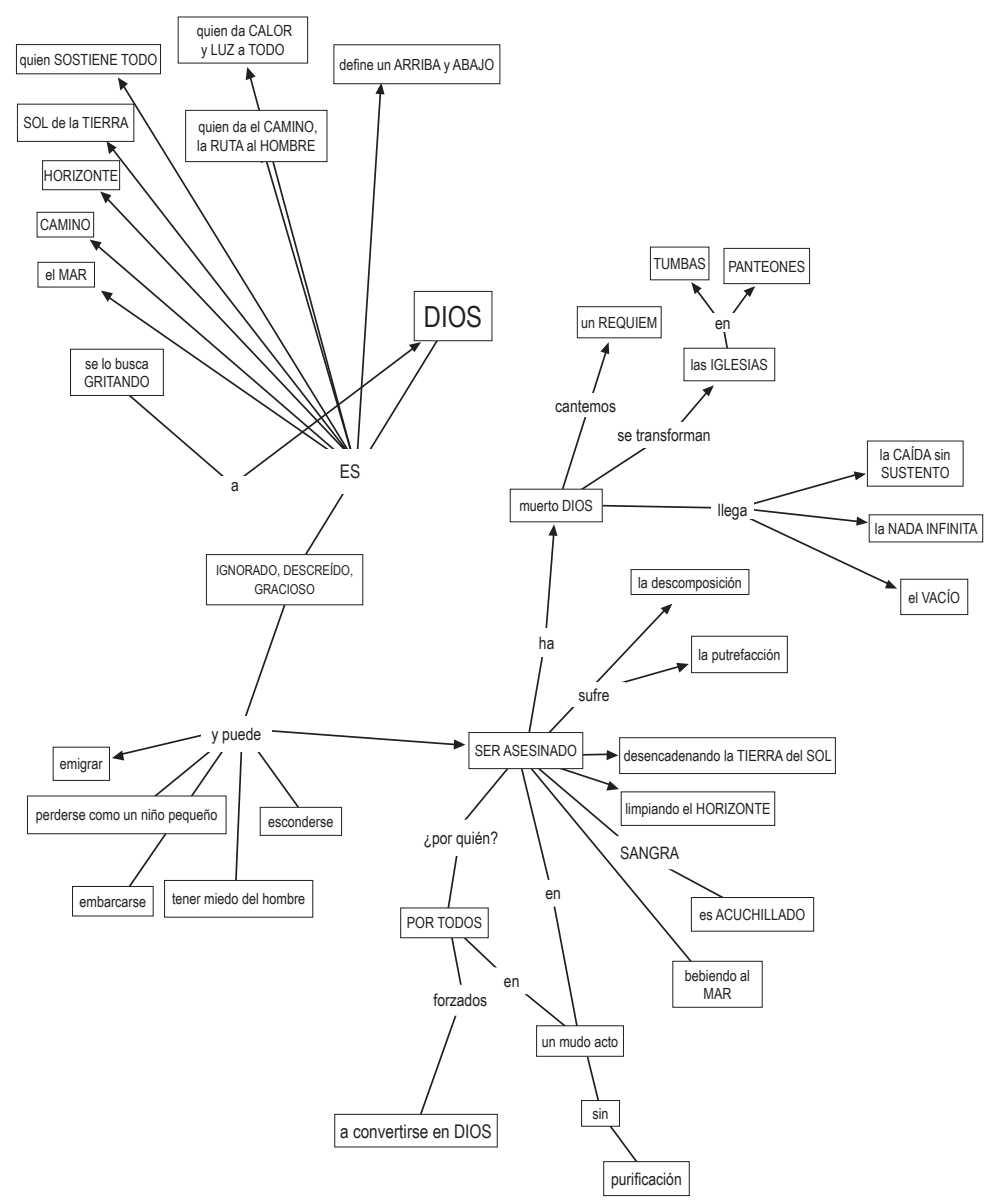




\section{...y haciendo uso de las nuevas tecnologías}

Concluyendo este trabajo queremos resaltar la riqueza que puede significar el uso de un blog de cátedra para el trabajo de los alumnos en su casa. Como señala Tiscar Lara, llamamos weblogs educativos o edublogs a

aquellos blogs que apoyan un proceso de enseñanza-aprendizaje en un contexto educativo y que presentan varias ventajas: fácil uso, gratuito, autoría compartida, acceso desde cualquier lugar, publicación cronológica, integrador de otras herramientas (Web 2.0), tematización por categorías, enlaces permanentes (archivo, hemeroteca), interactividad (comentarios) y sindicación RSS ${ }^{12}$.

El blog permite que los alumnos posean virtualmente todos los materiales preparados por el docente desde el programa de contenidos de la asignatura hasta todo el material de lectura requerido para el cursado de la asignatura Antropología Filosófica. El porcentaje de alumnos que cuentan con conexión a Internet de banda ancha en su casa es alto y, por lo tanto, es accesible a este tipo de propuestas; si bien, nunca se ha dejado de presentar posibilidades alternativas para aquellos alumnos que tuvieran dificultad para el acceso a Internet.

También el edublog permite el uso de la multimedia a través de producciones propias o por medio de múltiples herramientas que ofrece Internet para acceder a un blog gratuito con contenidos multimedia como canciones, video clips o audios. La utilización de multimedia refuerza el contenido filosófico abordado, ayuda a anclarlo en un medio más amigable para el adolescente y actúa como generador de relaciones entre el contenido filosófico o reflexivo planteado por la cátedra y la vivencia más personal del adolescente. 
Para los alumnos es una gran alternativa comenzar a hacer uso de Internet no solo como pasatiempo o comunicador entre pares, sino como medio de estudio y de trabajo académico escolar; permite la producción de pequeños textos que pueden ser compartidos a través de los comentarios o posteos que realizan, logrando así que la realización escrita pase de un plano meramente privado a uno semi-público que posibilita conocer la producción de otro, el cómo y qué piensa y cómo traduce esto en una redacción.

Para el docente es un desafío la producción de contenidos y la evaluación de las propuestas realizadas ya sea para traducir la producción del alumnado en datos de acreditación de la asignatura o para identificar si la actividad planteada a través del uso de las nuevas tecnologías permite alcanzar los objetivos de enseñanza-aprendizaje planteados.

\section{Conclusión}

El tiempo de la fe no ha caducado, pero es necesario expresarla de un modo accesible al hombre contemporáneo que vive inmerso en la cultura secular, y la formación en filosofía puede ser uno de los caminos para llegar a los frutos de la vivencia de la fe en un pensador radical como Emmanuel Mounier y vislumbrar la riqueza de vida que presenta el pensamiento cristiano, y dentro de este el personalismo, para nuestra cultura urbana posmoderna, para las personas que viven en medio de esta historia y buscan desplegar con sed de sentido toda su existencia.

Hemos presentado nuestra búsqueda de cinco años de intensa actividad docente, en ella hemos plasmado nuestra inquietud de enseñar y aprender filosofía en un aula con jóvenes de 17 años que viven, como sus docentes, en una sociedad caracterizada por su carácter multiétnico, por ende multicultural y plurirreligioso. 
Siempre hemos considerado que la dignidad personal y la dignidad de cada persona humana es esa propuesta vital que permite descubrir la presencia de Dios en el encuentro con el otro y favorecer la vida comunitaria como lugar de esta presencia y, por ello, hemos optado por realizar un planteo que parta de pensadores que nos conducen a esta experiencia. Este es nuestro aporte en esta búsqueda.

\section{Notas}

1 Cfr. A. Cerletti y W. Kohan, La filosofía en la escuela. Caminos para pensar su sentido, Buenos Aires, la UBA y los profesores, Universidad de Buenos Aires, 1996.

2 La expresión "boludo/a" que puede ser utilizada como insulto, se ha impuesto socialmente en Argentina como un modo coloquial y cercano de dirigirse a otra persona, en general un par.

3 Cfr. A. Gesché, El destino (Dios para pensar III), Colección "Verdad e Imagen", $n^{\circ}$ 148, Sígueme, Salamanca, 2001. La obra El destino, del teólogo francés Adolphe Gesché, es parte de una colección dogmática elaborada por el autor denominada Dios para pensar que recorre puntos centrales de las preguntas sobre Dios: el mal, el hombre, Dios y el cosmos, el destino, Jesucristo, el sentido. Este tomo de la colección enfrenta el desafío de presentar la fe como medio de salvación y plenitud de la vida del hombre. Dado que la actualidad no posee los códigos para leer la propuesta de fe cristiana, el autor se plantea hacer inteligible el discurso de la salvación dando cuenta de qué imagen de Dios es necesaria presentar a los hombres para hacer legible la experiencia de la fe.

4 Cfr. J. Gafo, Bioética Teológica, Bilbao, Desclée de Bouwer, 2003, 82. El autor realiza un estudio del tema analizando la propuesta de H. Küng, Proyecto de una ética mundial, Madrid, 1990.

5 J. Gelman, Vadarkablar. Publicado en Cólera Buey, Buenos Aires, Biblioteca Breve Ed. Seix Barral, 1994, p. 101.

6 A. López Quintás, El personalismo dialógico y su fecundidad, En Persona: revista iberoamericana de personalismo comunitario, $\mathrm{N}^{\circ}$ 8, 2008, 9. Disponible online en 〈http://www.personalismo.net/persona/sites/default/files/10FigdelPers.pdf), última vista 10/03/2011. 
7 F. J. Vaquero Oroquieta, El movimiento personalista en España, en ARBIL, Anotaciones de Pensamiento y Crítica", No 61, Foro Arbil, Zaragoza, España, disponible online en «tttp://www.arbil.org/arbid61.htm>, última vista 05/04/2011.

8 Para mayor información se puede consultar el artículo "The Black Eyed Peas" de la enciclopedia libre Wikipedia.

9 Andrés Calamaro, La libertad.

10 La red conceptual se realiza siguiendo a Noro, J. E., Pensar para educar. Filosofía y educación, ed. Didascalia, Santa Fé, Argentina, $2005,247$.

11 A. Calvo, El personalismo de E.Mounier, en ARBIL, Anotaciones de Pensamiento y Crítica, No 61, Foro Arbil, Zaragoza, España, en 〈http://www.arbil.org/arbi-d61.htm〉, última vista 10/03/2011.

12 Conceptos de Tiscar Lara citados en Albarello F., Canella R., Tsuji T., Internet como medio de comunicación estratégica en la formación del profesorado, en Razón y Palabra, N 63, 2008, disponible online en 〈http://www.razonypalabra.org.mx/n63/falbarello.html», última vista 10/03/2011.

\section{Bibliografía}

\section{Textos}

Cerletti, Alejando y Walter Kohan

1996 La filosofía en la escuela. Caminos para pensar su sentido. Buenos Aires: la UBA y los profesores, Universidad de Buenos Aires.

Croci, Paula y Mariano Mayer

1998 Biografía de la piel. Esbozo para una enciclopedia del tatuaje. Buenos Aires: Perfil Libros.

Gafo, Javier

2003 Bioética Teológica. Bilbao: Desclée de Bouwer.

Gallagher, Jim

1997 La obra de una mujer: Chiara Lubich. El Movimiento de los Focolares y su fundadora. Buenos Aires-Madrid, 199.

Gelman, Juan

1994 Cólera Buey. Buenos Aires: Seix Barral.

Gelman, Juan

2004 País que fue será. Buenos Aires: Seix Barral.

Gesché, Adolphe

2001 El destino (Dios para pensar III). Salamanca: Sígueme. 
Guita, María Estela

1999 Educación y valores en adolescentes de la posmodernidad desde una perspectiva personalista. Tesis de la Lic. en Ciencias de la Educación. Universidad Católica de Córdoba: 26.

Noro, Jorge Eduardo

2005 Pensar para educar. Filosofía y educación. Santa Fé: Ed. Didascalia.

Sartori, Giovanni

1998 Homo videns. La sociedad teledirigida. Buenos Aires: Ed. Taurus.

Sgreccia, Elio

1996 Manual de Bioética, Instituto de Humanismo en Ciencias de la Salud. México: Ed. Diana.

Vattimo, Gianni

1990 “Posmodernidad: ¿una sociedad transparente?”, en: En torno a la posmodernidad. Barcelona: Ed. Ántropos.

\section{Referencias electrónicas}

Albarello Francisco, Canella Rubén, Tsuji Teresa

Internet como medio de comunicación estratégica en la formación del profesorado, en Razón y Palabra, № 63, 2008, disponible online en 〈http://www.razonypalabra.org.mx/n63/ falbarello.html, última vista 10/03/2011.

Calvo, Antonio

El personalismo de E.Mounier, en ARBIL, Anotaciones de Pensamiento y Crítica", No 61, Foro Arbil, Zaragoza, España, en 〈http://www.arbil.org/arbi-d61.htm〉, última vista $10 / 03 / 2011$.

López Quintás, Alfonso

El personalismo dialógico y su fecundidad, Persona: revista iberoamericana de personalismo comunitario, No 8, 2008, disponible online en http://www.personalismo.net/ persona/sites/default/files/10FigdelPers.pdf, última vista 10/03/2011.

Vaquero Oroquieta, Fernando José

El movimiento personalista en España, en ARBIL, Anotaciones de Pensamiento y Crítica, No 61, Foro Arbil, Zaragoza, España, disponible online en 〈http://www.arbil.org/arbid61.htm>, última vista 05/04/2011. 